\title{
Artificial Neural Network Model for Compressive Strength of Lateritic Blocks
}

\author{
C.E Okere, J.I. Arimanwa, and J.C. Theke
}

Department of Civil Engineering, Federal University of Technology, P.M.B. 1526, Owerri, Nigeria

\begin{abstract}
Lateritic soil are locally abundant and relatively cheap to be used for block production. Its use has gone a long way in reducing the cost of block production and construction work in general. In order to optimize the usefulness of lateritic soil, there is need to model the properties of lateritic blocks. Compressive strength is an important property of lateritic block that must be known, but it cannot be guessed easily due to the block mix proportion and processes. Statistical models used in predicting the properties of lateritic blocks operate on restricted range of data. That is, the model cannot predict input data that are outside the range of data used in developing the model. The need for a model that can predict the compressive strength of lateritic blocks for any given mix ratio became necessary. This study developed Artificial Neural Network model for predicting the compressive strength of lateritic blocks. Lateritic blocks were produced with mix ratios ranging from 1:4 to 1:12. The blocks were cured for 7,14 and 28 days. The 28th day experimental results and results obtained from literatures on similar works were used to formulate the model. The test data were a total of 155 samples.The maximum compressive strength predicted by the model was $3.06 \mathrm{~N} / \mathrm{mm}^{2}$ corresponding to a mix ratio of 0.4:1:4 of water-cement ratio, cement and lateritic soil. The model accuracy was tested using Fisher test. The result of the Fisher test computations obtained 1.008 for calculated $F$ and 3.5 for $F$ obtained from the table. Hence the model satisfied the test. The model result also compares favourably with the experimental result.
\end{abstract}

Keywords: Artificial Neural Network, Compressive strength, Lateritic blocks, Prediction.

\section{INTRODUCTION}

Lateritic blocks are composite materials made up of cement, laterite and water, moulded into various shapes and sizes. These blocks are manufactured by the process of mixing the constituent materials, molding and ejecting of formed blocks. The quality of blocks differs from place to place as a result of discrepancy in the properties of constituent materials, the mix proportion of the constituents and method employed in production.

According to [1] lateritic blocks were made by the Nigerian Building and Road Research Institute (NBRRI) and used for the construction of a bungalow. NBRRI proposed the following minimum specification as requirements for lateritic blocks, bulk density of $1810 \mathrm{~kg} /$ $\mathrm{m}^{3}$, water absorption of $12.5 \%$, and compressive strength of $1.65 \mathrm{~N} / \mathrm{mm}^{2}$ with maximum cement content fixed at $5 \%$.

The compressive strength of block is one of the most important and useful property of blocks/concrete. It is used as a qualitative measure for other properties of blocks. Compressive strength of block must be known in other to model the behavior of laterite block structure. It cannot be guessed easily due to the constituent proportion of the block and the production processes [2]. The compressive strength of block is generally determined by testing blocks made in laboratory or field with the universal testing machine after 28 days curing. Loads are applied gradually till the specimen fails. Then the load at failure divided by the cross sectional area of specimen gives the compressive strength of blocks.

Some research works have been carried out on the compressive strength of blocks, few will be discussed in this work. [3] Worked on the production and testing of lateritic interlocking blocks. The interlocking blocks were produced with lateritic samples obtained from four different locations and stabilized with $0 \%, 5 \%, 10 \%$ and $15 \%$ cement content. In their work some properties of the lateritic blocks were optimized. It was deduced from the research that all the stabilized lateritic interlocking blocks satisfied the minimum 28 days wet compressive strength of $1.0 \mathrm{~N} / \mathrm{mm}^{2}$ recommended by the Nigeria Building and Road Research Institute.

[4]Researched on the suitability and advantages of using laterite as a soilcrete block material. The soilcrete blocks were produced were produced using $6 \%$ to $10 \%$ cement stabilization and a compressive strength of $2.15 \mathrm{~N} / \mathrm{mm}^{2}$ with $10 \%$ cement content was obtained. It was observed that compressive strength obtained was higher than the 
recommended value of $1.65 \mathrm{~N} / \mathrm{mm}^{2}$ proposed by the Nigerian Building and Road Research Institute (NBRRI) for laterite blocks.

The reliability of any model to correctly predict the block properties depends on how good the model is. Conventional methods of predicting 28 days compressive strength of blocks are based on statistical analysis which suitable regression equations have been developed to model such prediction problems. These statistical models have been observed to operate on restricted range of data. That is, the model is developed with limited range of values and if values inputted into the model are outside the proposed range, an error result is obtained. [5]It was stated in his work that choosing a suitable regression equation involves technique and experience. He highlighted that such prediction models have been developed with a fixed equation form based on a limited number of data. Therefore if the new data is quite different from the original data, the model is expected to update not only its coefficients but also its equation form.

Artificial Neural Network (ANN) is not restricted to a particular range of data or information, but needs sufficient input-output data. Artificial Neural Network (ANN) learn from data examples presented to them and use these data to adjust their weights in an attempt to capture the relationship between the model input variables and their corresponding outputs. Artificial Neural Network are data processing systems consisting of a large number of simple, highly interconnected processing elements (artificial neurons) in an architecture inspired by the structure of the central cortex of the brain. They have the ability to learn from experience in order to improve their performance and to adapt themselves to changes in the environment $[6,7]$.

The importance of Artificial Neural Network cannot be overemphasized, as it has been used in so many areas as applied to Civil Engineering and precisely in the prediction of the compressive strength of materials. Some authors have also used ANN in structural engineering.[8] Applied ANN for predicting properties of concrete. [5] Neural Network was also used to develop a model for predicting the compressive strength of high strength concrete. In his work, 368 different high strength concrete mix design data were collected from the laboratory. Test data were assembled for high strength concrete containing cement, coarse aggregate, fine aggregate, water, fly ash, silica fume, granulated graded blast furnace slag and superplasticizer. These data were gathered for compressive strength of concrete at 28 days and range of compressive strength was from 40 to 140 MPa.

[9] The research was on the prediction of elastic modulus of concrete using artificial neural network model. In his work he was able to establish the model using 800 mixes which were supplied to the network. He stated that the coefficient of correlation, $\mathrm{R}$, values of the data used for training, testing and validating the network were respectively greater than 0.90 , implying that the data used in the network had a good fit. He also stated that the result obtained from his network when compared with the regression and experimental values were found to be very close.

\section{MATERIALS AND METHOD}

The following materials were used for the experiment;

i. Elephant Supaset cement, of class 4.25 and a brand of Ordinary Portland Limestone cement was used.

ii. The laterite was obtained from Mgbirichi, Owerri L.G.A, Imo State.It was subjected to various physical property tests and analysis.

iii. Water used for lateritic block production and curing is potable water obtained from a borehole in FUTO. The water was in conformity to the specification of [10].

\subsection{Development of Artificial Neural Network Model}

In this work, Feed-Forward Artificial Neural Network with Levenberg-Marquardt algorithm was used to develop the model for predicting the compressive strength of lateritic blocks. MATLAB 2014b software was the platform used. The test data were a total of 155 samples. The data were obtained from laboratory and few from similar literatures on compressive strength of lateritic blocks. The data was prepared and allowed to cover the range of inputs for which the network will be used. It was preprocessed (this is provided automatically when the network is created and it becomes part of the network object, so that whenever the network is used the data coming into the network is preprocessed in the same way.) Then was divided into subsets. The network object was created. The function "feedforwardnet" created a multi-layered network. The "configure" command configured the network object and also initialized the weights and biases of the network. When there was need to reinitialize the network, the "init" command was used. The network was ready for training, it was trained for function approximation (nonlinear regression). The training process required a set of examples of proper network behavior that is network inputs " $p$ " and target outputs " $\mathrm{t}$ ". The process of training the neural network involved tuning the values of the weights and biases of the network to optimize network performance. The default performance function for feedforward networks is mean square error "mse". The training was implemented using incremental training. The weights and biases of the network are updated each time an input is presented to the network. The algorithm used to optimize the performance 
function is Levenberg Marquardt backpropagation algorithm "trainlm". It performed the computations backwards through the network. Once the network was trained and validated, the object was ready to be used in calculating the network response to any input.

Different architectures were obtained for compressive strength as shown in the Table 2.The best trained network was selected. This is the network with the least mean square error. The best trained Artificial Neural Network model data for 28th day compressive strength of lateritic blocks is the bolded architecture as shown in Table 2. The best trained network was used to predict results for compressive strength of lateritic blocks. The predicted results from Artificial Neural Network for 28th day compressive strength is presented in Table 3.

\section{RESULTS AND DISCUSSION}

The Artificial Neural Network model was carried out for the compressive strength of lateritic blocks.The result of compressive strength is presented in Table 1. The best trained network architecture for compressive strength of Artificial Neural Network and experimental result is 0.4234 . lateritic blocks is 3-71-1 with momentum and learning rate of 0.8 and 0.04 respectively as shown in Table 2. This is the bolded architecture. It has a transfer function of Logsig and Purelin and mean square error of 0.0000183 . It is made up of one hidden layer and one output layer. The best trained architecture, 3-71-1 with mix ratios inputted was used to predict the compressive strength of lateritic blocks as shown in Table 3. Training window showing predicted result from Artificial Neural Network model for compressive strength of lateritic blocks is as shown in Fig 1. Results were obtained, the maximum result obtained was $3.0600 \mathrm{~N} / \mathrm{mm}^{2}$ while the minimum was $1.8422 \mathrm{~N} / \mathrm{mm}^{2}$. The adequacy of the model was tested using Fisher test as shown in Table 4. The result of the Fisher test computation obtained 1.008 for calculated degree of freedom "F" and 3.5 for "F" obtained from the table. The model was adequate since the calculated value was less than the value obtained from the "F" table. Results obtained from the model was compared with results from experiment as presented in Table 5. The results were analyzed by their percentage difference. The highest percentage difference from

Table.1: Results of 28th, 14th and 7th day Compressive strength test of Lateritic blocks

\begin{tabular}{|l|l|l|l|l|}
\hline $\begin{array}{l}\text { Experiment } \\
\text { No }\end{array}$ & $\begin{array}{l}\text { Mix ratios } \\
\text { (w/c:cement:laterite) }\end{array}$ & $\begin{array}{l}\text { 28th day } \\
\text { Compressive strength } \\
\boldsymbol{f}_{\boldsymbol{c u}}\left(\mathbf{N} / \mathbf{m m}^{\mathbf{2}}\right)\end{array}$ & $\begin{array}{l}\mathbf{1 4 t h} \text { day } \\
\text { Compressive strength } \\
\boldsymbol{f}_{\boldsymbol{c u}}\left(\mathbf{N} / \mathbf{m m}^{\mathbf{2}}\right)\end{array}$ & $\begin{array}{l}\text { 7th day } \\
\text { Compressive strength } \\
\boldsymbol{f}_{\boldsymbol{c u}}\left(\mathbf{N} / \mathbf{m}^{\mathbf{2}}\right)\end{array}$ \\
\hline $\mathbf{1}$ & $0.40: 1: 4$ & 3.06 & 1.91 & 1.43 \\
\hline $\mathbf{2}$ & $0.46: 1: 5$ & 2.90 & 1.74 & 1.23 \\
\hline $\mathbf{3}$ & $0.50: 1: 6$ & 2.84 & 1.65 & 1.04 \\
\hline $\mathbf{4}$ & $0.63: 1: 7$ & 2.64 & 1.61 & 0.94 \\
\hline $\mathbf{5}$ & $0.70: 1: 8$ & 2.51 & 1.45 & 0.81 \\
\hline $\mathbf{6}$ & $0.74: 1: 9$ & 2.48 & 1.20 & 0.72 \\
\hline $\mathbf{7}$ & $0.86: 1: 10$ & 2.21 & 0.96 & 0.64 \\
\hline $\mathbf{8}$ & $0.88: 1: 11$ & 2.09 & 0.92 & 0.58 \\
\hline $\mathbf{9}$ & $1.0: 1: 12$ & 1.85 & 0.79 & 0.54 \\
\hline
\end{tabular}

Table 2: Different Architectures for compressive strength of lateritic block with Artificial Neural Network model

\begin{tabular}{|c|c|c|c|c|c|c|c|c|}
\hline Network & Architecture & L-R & $\mathbf{M}$ & $\begin{array}{l}\text { Transfer } \\
\text { Function For } \\
\text { hidden layers }\end{array}$ & $\begin{array}{l}\text { Transfer } \\
\text { function for } \\
\text { output layer }\end{array}$ & $\begin{array}{l}\text { Time } \\
\text { (s) }\end{array}$ & $\begin{array}{l}\text { No of } \\
\text { Iteration }\end{array}$ & $\begin{array}{l}\text { Mean Square } \\
\text { Error (MSE) }\end{array}$ \\
\hline $\mathrm{NNTC}_{15}$ & $3-39-1$ & 0.04 & 0.8 & Tansig & Purelin & $0: 00: 00$ & 14 & 0.0790 \\
\hline $\mathrm{NNTC}_{16}$ & $3-25-1$ & 0.04 & 0.8 & Tansig & Purelin & 0:00:00 & 15 & 0.0000678 \\
\hline $\mathrm{NNT}_{17}$ & $3-27-1$ & 0.04 & 0.8 & Tansig & Purelin & 0:00:01 & 50 & 0.000211 \\
\hline $\mathrm{NNT}_{18}$ & $3-55-1$ & 0.04 & 0.8 & Satlins & Satlins & 0:00:00 & 14 & 0.00069 \\
\hline $\mathrm{NNTC}_{19}$ & $3-42-1$ & 0.04 & 0.8 & Logsig & Purelin & 0:00:00 & 7 & 0.0018 \\
\hline $\mathrm{NNT}_{20}$ & 3-33-1 & 0.04 & 0.8 & Purelin & Logsig & 0:00:00 & 8 & 0.2832 \\
\hline $\mathrm{NNTC}_{21}$ & $3-22-1$ & 0.04 & 0.8 & Tansig & Tansig & 0:00:04 & 239 & 0.0085 \\
\hline $\mathrm{NNTC}_{22}$ & $3-44-1$ & 0.04 & 0.8 & Tansig & Purelin & 0:00:00 & 9 & 0.0000310 \\
\hline $\mathrm{NNTC}_{23}$ & $3-67-1$ & 0.04 & 0.8 & Tansig & Purelin & 0:00:00 & 11 & 0.0243 \\
\hline
\end{tabular}




\begin{tabular}{|l|l|l|l|l|l|l|l|l|}
\hline NNTC $_{\mathbf{2 4}}$ & $3-96-1$ & 0.04 & 0.8 & Tansig & Logsig & $0: 00: 00$ & 10 & 0.2744 \\
\hline NNTC $_{\mathbf{2 5}}$ & $3-42-1$ & 0.04 & 0.8 & Logsig & Logsig & $0: 00: 00$ & 13 & 0.2712 \\
\hline NNTC $_{\mathbf{2 6}}$ & $3-50-1$ & 0.04 & 0.8 & Logsig & Logsig & $0: 00: 00$ & 30 & 0.2713 \\
\hline NNTC $_{\mathbf{2 7}}$ & $3-88-1$ & 0.04 & 0.8 & Purelin & Tansig & $0: 00: 00$ & 10 & 0.0287 \\
\hline NNTC $_{\mathbf{2 8}}$ & $3-58-1$ & 0.04 & 0.8 & Tansig & Purelin & $0: 00: 00$ & 12 & 0.000280 \\
\hline NNTC $_{\mathbf{2 9}}$ & $3-38-1$ & 0.04 & 0.8 & Tansig & Purelin & $0: 00: 00$ & 7 & 0.0305 \\
\hline NNTC $_{\mathbf{3 0}}$ & $3-28-1$ & 0.04 & 0.8 & Satlins & Purelin & $0: 00: 00$ & 8 & 0.0017 \\
\hline NNTC $_{\mathbf{3 1}}$ & $3-21-1$ & 0.04 & 0.8 & Satlins & Purelin & $0: 00: 00$ & 10 & 0.000809 \\
\hline NNTC $_{\mathbf{3 2}}$ & $3-52-1$ & 0.04 & 0.8 & Satlins & Poslin & $0: 00: 00$ & 19 & 0.2876 \\
\hline NNTC $_{\mathbf{3 3}}$ & $3-46-1$ & 0.04 & 0.8 & Poslin & Purelin & $0: 00: 00$ & 11 & 0.0396 \\
\hline NNTC $_{\mathbf{3 4}}$ & $3-71-1$ & 0.04 & 0.8 & Logsig & Purelin & $0: 00: 22$ & 473 & 0.0000183 \\
\hline NNTC $_{\mathbf{3 5}}$ & $3-23-1$ & 0.04 & 0.8 & Tansig & Purelin & $0: 00: 00$ & 22 & 0.000102 \\
\hline
\end{tabular}

Table 3: Predicted result from Artificial Neural Network for 28th day Compressive strength of Lateritic blocks

\begin{tabular}{|l|l|l|}
\hline $\begin{array}{l}\text { Experiment } \\
\text { No }\end{array}$ & $\begin{array}{l}\text { Mix ratios } \\
\text { (w/c:cement:laterite) }\end{array}$ & $\begin{array}{l}\text { Compressive } \\
\text { strength } \\
\boldsymbol{f}_{\boldsymbol{c u}}\left(\mathbf{N} / \mathbf{m m}^{\mathbf{2}} \text { ) }\right.\end{array}$ \\
\hline $\mathbf{1}$ & $0.40: 1: 4$ & 3.0600 \\
\hline $\mathbf{2}$ & $0.46: 1: 5$ & 2.9000 \\
\hline $\mathbf{3}$ & $0.50: 1: 6$ & 2.8400 \\
\hline $\mathbf{4}$ & $0.63: 1: 7$ & 2.6404 \\
\hline $\mathbf{5}$ & $0.70: 1: 8$ & 2.5100 \\
\hline $\mathbf{6}$ & $0.74: 1: 9$ & 2.4776 \\
\hline $\mathbf{7}$ & $0.86: 1: 10$ & 2.2140 \\
\hline $\mathbf{8}$ & $0.88: 1: 11$ & 2.0866 \\
\hline $\mathbf{9}$ & $1.0: 1: 12$ & 1.8422 \\
\hline
\end{tabular}

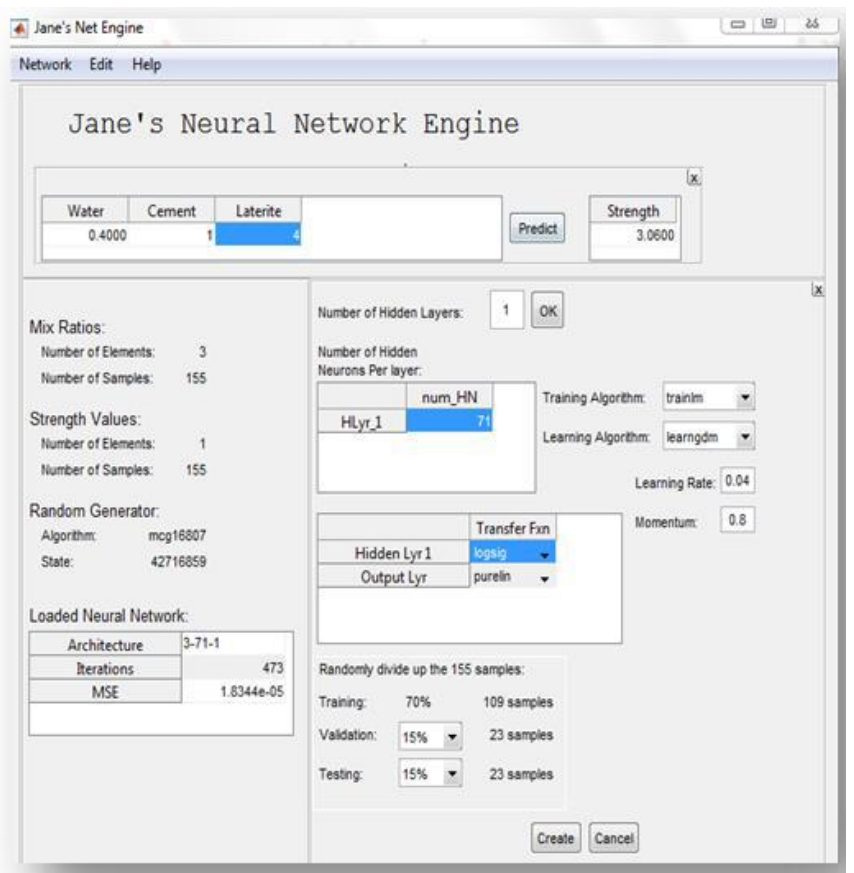

Fig 1: Training window showing predicted result from Artificial Neural Network Model for compressive strength of lateritic blocks. 
Table 4: Fisher test computations for Artificial Neural Network Compressive Strength Model

\begin{tabular}{|l|l|l|l|l|l|l|l|}
\hline $\begin{array}{l}\text { Exp. } \\
\text { No }\end{array}$ & $\begin{array}{l}\text { Mix ratios } \\
\text { (w/c:cement:laterite) }\end{array}$ & $\begin{array}{c}\boldsymbol{Y}_{\text {observed }} \\
\left(\boldsymbol{Y}_{\boldsymbol{O}}\right)\end{array}$ & $\begin{array}{c}\boldsymbol{Y}_{\text {predicted }} \\
\left(\boldsymbol{Y}_{\boldsymbol{P}}\right)\end{array}$ & $\boldsymbol{Y}_{\boldsymbol{O}^{-}} \boldsymbol{y}_{\boldsymbol{O}}$ & $\boldsymbol{Y}_{\boldsymbol{P}^{-} \boldsymbol{y}_{\boldsymbol{P}}}$ & $\left(\boldsymbol{Y}_{\boldsymbol{O}}-\boldsymbol{y}_{\boldsymbol{O}}\right)^{\mathbf{2}}$ & $\left(\boldsymbol{Y}_{\boldsymbol{P}}-\boldsymbol{y}_{\boldsymbol{P}}\right)^{\mathbf{2}}$ \\
\hline $\mathbf{1}$ & $0.40: 1: 4$ & 3.0600 & 3.0600 & 0.5511 & 0.5522 & 0.3037112 & 0.3049248 \\
\hline $\mathbf{2}$ & $0.46: 1: 5$ & 2.9000 & 2.9000 & 0.3911 & 0.3922 & 0.1529592 & 0.1538208 \\
\hline $\mathbf{3}$ & $0.50: 1: 6$ & 2.8400 & 2.8400 & 0.3311 & 0.3322 & 0.1096272 & 0.1103568 \\
\hline $\mathbf{4}$ & $0.63: 1: 7$ & 2.6400 & 2.6404 & 0.1311 & 0.1326 & 0.0171872 & 0.0175827 \\
\hline $\mathbf{5}$ & $0.70: 1: 8$ & 2.5100 & 2.5100 & 0.0011 & & 0.0000012 & 0.0000048 \\
\hline $\mathbf{6}$ & $0.74: 1: 9$ & & & & 0.0022 & & \\
\hline $\mathbf{7}$ & $0.86: 1: 10$ & 2.4800 & 2.4776 & -0.0289 & -0.0302 & 0.0008352 & 0.0009120 \\
\hline $\mathbf{8}$ & $0.88: 1: 11$ & 2.2100 & 2.2140 & -0.2989 & -0.2938 & 0.0893412 & 0.0863184 \\
\hline $\mathbf{9}$ & $1.0: 1: 12$ & 1.8500 & 1.8422 & -0.6589 & -0.6656 & 0.4341492 & 0.4430233 \\
\hline $\mathbf{\Sigma}$ & & 22.580 & 22.570 & & & 1.283288 & 1.294353 \\
\hline & & $y_{O}=2.5089$ & $y_{P}=2.5078$ & & & & \\
\hline
\end{tabular}

Legend: $\mathrm{y}=\sum \frac{Y}{n}$

$\mathrm{y}=$ represents the response

$\mathrm{n}=$ the number of responses

Applying Eqn (1):

$\mathrm{F}=\frac{S_{1}^{2}}{S_{2}^{2}}(1)$

$S_{O}^{2}=\frac{1.283288}{8}=0.160411$

Table.5: Comparison of Artificial Neural Network Simulated Results with Experimental Result for Compressive Strength of Lateritic Block

\begin{tabular}{|l|l|l|l|l|l|}
\hline $\begin{array}{l}\text { Experiment } \\
\text { No }\end{array}$ & $\begin{array}{l}\text { Mix ratios } \\
\text { (w/c: } \\
\text { cement: } \\
\text { laterite) }\end{array}$ & $\begin{array}{l}\text { Experiment } \\
\text { Result } \mathbf{( E )} \\
\left(\mathbf{N} / \mathbf{m m}^{\mathbf{2}}\right)\end{array}$ & $\begin{array}{l}\text { Neural } \\
\text { Network } \\
\text { Prediction }(\mathbf{N}) \\
\left(\mathbf{N} / \mathbf{m m}^{\mathbf{2}}\right)\end{array}$ & Difference & $\begin{array}{l}\text { Percentage } \\
\text { difference } \\
(\boldsymbol{\%})=\mid(\boldsymbol{E}-\boldsymbol{N}) \times \frac{\mathbf{1 0 0}}{\mathbf{1}}\end{array}$ \\
\hline $\mathbf{1}$ & $0.40: 1: 4$ & 3.0600 & 3.0600 & 0.0000 & 0.0000 \\
\hline $\mathbf{2}$ & $0.46: 1: 5$ & 2.9000 & 2.9000 & 0.0000 & 0.0000 \\
\hline $\mathbf{3}$ & $0.50: 1: 6$ & 2.8400 & 2.8400 & 0.0000 & 0.0000 \\
\hline $\mathbf{4}$ & $0.63: 1: 7$ & 2.6400 & 2.6404 & -0.0004 & 0.0151 \\
\hline $\mathbf{5}$ & $0.70: 1: 8$ & 2.5100 & 2.5100 & 0.0000 & 0.0000 \\
\hline $\mathbf{6}$ & $0.74: 1: 9$ & 2.4800 & 2.4776 & 0.0024 & 0.0968 \\
\hline $\mathbf{7}$ & $0.86: 1: 10$ & 2.2100 & 2.2140 & -0.0040 & 0.1806 \\
\hline $\mathbf{8}$ & $0.88: 1: 11$ & 2.0900 & 2.0866 & 0.0034 & 0.1629 \\
\hline $\mathbf{9}$ & $1.0: 1: 12$ & 1.8500 & 1.8422 & 0.0078 & 0.4234 \\
\hline
\end{tabular}

\section{CONCLUSION}

In conclusion, compressive strengths were obtained experimentally from various mix ratios for the lateritic blocks. The maximum values for the 28 th, 14 th and 7 th day are $3.06 \mathrm{~N} / \mathrm{mm}^{2}, \quad 1.91 \mathrm{~N} / \mathrm{mm}^{2}$ and $1.43 \mathrm{~N} / \mathrm{mm}^{2}$ respectively. The 28 th day compressive strength was used to develop the Artificial Neural Network model. The
$S_{P}^{2}=\frac{1.294353}{8}=0.161794$

$\mathrm{F}=\frac{0.161794}{0.160411}=1.008$

From F-table, $F_{0.95}(8,8)=3.5$

The calculated $\mathrm{F}$ is less than the $\mathrm{F}$ obtained from the table. Hence the model is adequate. 
from the "F" table. Percentage difference were obtained

from the comparison of Artificial Neural Network model result with experimental result. The maximum percentage difference was $0.4234 \%$ as shown in Table 5 .

\section{REFERENCES}

[1] Wilson, U.N., Raji, S.A. \& Alomaja, J.A. (2016). Comparative review on the use of sandcrete blocks and laterite-cement bricks in Nigeria. Ethiopian International Journal of Multidisciplinary Research, 3(3), 32-44.

[2] Anslem, C.I. (2015). Prediction of Compressive Strength of Lateritic-Palm Kernel Shell Concrete. An unpublished M.Eng Thesis submitted to the department of Civil Engineering, FUTO.

[3] Akeem, A.R., Olugbenro, O.F. \& Kehinde, J.A. (2012). Production and testing of lateritic interlocking blocks. Journal of Construction in Developing Countries, 17(1), 33-48.

[4] Okere, C.E. (2017). Suitability and advantages of using laterite as a soilcrete block material. International Journal of Architectural Science and Civil Engineering, 1(1).

[5] Hakim, S.J., Noorzaei, J., Jaafar, M.S., Jameel, M., \& Mohammadhassani, M. (2011). Application of artificial neural networks to predict compressive strength of high strength concrete.International Journal of the Physical Sciences, 6(5), 975-981.

[6] Hola, J. \& Schabowicz, K. (2005). Application of artificial neural networks to determine concrete compressive strength based on Non-destructive tests. Journal of Civil Engineering and Management, 11(1), 23-32.

[7] Mansour, M.Y., Dideli, M., Lee Y.J. \& Zhang, J. (2004). Predicting the shear strength of reinforced concrete beams using artificial neural networks. Journal of Engineering Structures, 26, 781-799.

[8] Lee, S.C. (2003). Prediction of concrete strength using artificial neural networks. Journal of Engineering Structure, 25, 849-857.

[9] Cyril, O.N. (2014). Artificial neural network model for the Prediction of elastic modulus of concrete.An unpublished M.Eng Thesis submitted to the department of Civil Engineering, FUTO.

[10] British Standards Institution (2002). BS EN 1008:2002. Mixing water for concrete. Specification for sampling, testing and assessing the suitability of water, including water recovered from processes in the concrete industry, as mixing water for concrete. 